\title{
Embolism resistance as a key mechanism to understand adaptive plant strategies \\ Frederic Lens ${ }^{1}$, Aude Tixier ${ }^{2}$, Hervé Cochard ${ }^{2}$, John S Sperry ${ }^{3}$, Steven Jansen ${ }^{4}$ and Stephane Herbette ${ }^{2}$
}

\begin{abstract}
One adaptation of plants to cope with drought or frost stress is to develop wood that is able to withstand the formation and distribution of air bubbles (emboli) in its water conducting xylem cells under negative pressure. The ultrastructure of interconduit pits strongly affects drought-induced embolism resistance, but also mechanical properties of the xylem are involved. The first experimental evidence for a lower embolism resistance in stems of herbaceous plants compared to stems of their secondarily woody descendants further supports this mechanical-functional trade-off. An integrative approach combining (ultra)structural observations of the xylem, safetyefficiency aspects of the hydraulic pipeline, and xylem-phloem interactions will shed more light on the multiple adaptive strategies of embolism resistance in plants.

\footnotetext{
Addresses

${ }^{1}$ Naturalis Biodiversity Center, Leiden University, P.O. Box 9514, NL-2300 RA Leiden, The Netherlands

${ }^{2}$ INRA, UMR 547 PIAF, Clermont Université, Université Blaise Pascal, France

${ }^{3}$ Biology Department, University of Utah, 257S, 1400E, Salt Lake City, UT 84112, USA

${ }^{4}$ Institute for Systematic Botany and Ecology, Ulm University, Albert-Einstein Allee 11, D-89081 Ulm, Germany

Corresponding author: Lens, Frederic (frederic.lens@naturalis.nl)
}

Current Opinion in Plant Biology 2013, 16:287-292

This review comes from a themed issue on Physiology and metabolism

Edited by John Browse and Edward Farmer

For a complete overview see the Issue and the Editorial

Available online 28th February 2013

1369-5266/\$ - see front matter, (C) 2013 Elsevier Ltd. All rights reserved.

http://dx.doi.org/10.1016/j.pbi.2013.02.005

\section{Introduction}

According to the generally accepted cohesion-tension theory, capillary wicking of cell walls is the driving force in plants that creates a negative pressure, allowing transpiration to pull up water towards the leaves via a 3-D conduit network [1]. This negative pressure makes the liquid xylem sap metastable, and thus vulnerable to vaporization by cavitation [2]. Cavitated conduits may become air-filled or embolized, and can no longer transport water. Extensive embolism formation in the xylem can block most of the water flow, potentially leading to branch sacrifice or even plant death [3-4]. Therefore, the resistance to drought or frost-induced embolism is an important adaptive trait for the growth and survival of plants $\left[5,6,7^{\bullet \bullet}\right]$, evolving along with other strategies including rooting depth, leaf structure, shifts in biomass allocation, CAM metabolism, water storage and/or drought and frost avoidance.

This concise review describes how embolisms originate and spread into the conduit network, and highlights which mechanical properties of the xylem are involved in drought-induced embolism resistance. On the basis of original embolism measures in Arabidopsis, the mechanical-functional trade-offs may provide a novel additional explanation why some herbaceous flowering plant groups 'reinvented' wood development and turned again into the woody ancestral state (i.e. secondary woodiness).

\section{Why and how do embolisms originate and spread into the xylem? \\ Vulnerable hydraulic pathway}

When liquid water pressure drops below its saturated vapour pressure $\left(2.3 \mathrm{kPa}\right.$ absolute at $20^{\circ} \mathrm{C}$, or $-99 \mathrm{kPa}$ below atmospheric at sea level), it becomes metastable relative to the lower energy vapour phase [2]. As such, liquid water under negative pressure is vulnerable to cavitation: the abrupt phase change to vapour (cf. boiling). Spontaneous initiation of vapour bubbles in pure metastable water (homogenous nucleation) does not seem to be responsible for cavitation in plant xylem, because it occurs at pressures far more negative (between -30 and $-140 \mathrm{MPa}$ based on experimental measures [8]) than physiological xylem pressures (often between -0.1 and $-10 \mathrm{MPa}$ with exceptions to $>-20 \mathrm{MPa}[9-10])$. Instead, xylem cavitation is likely heterogeneous, triggered by nucleating sites, which are most likely either small gas bubbles in conduits or water-conduit wall boundaries experiencing weaker adhesion forces [11].

\section{Drought-induced embolism}

Experimental evidence points to 'air-seeding' as an important cause of embolism by drought stress [2,11-12]. As more negative sap pressure develops during drought, air is aspirated into the functional conduit through porous sections of the conduit wall. Once inside the conduit, these air bubbles may seed the phase change to vapour, causing the negative sap pressure to rise abruptly to near atmospheric. The gas bubble then is 
Figure 1

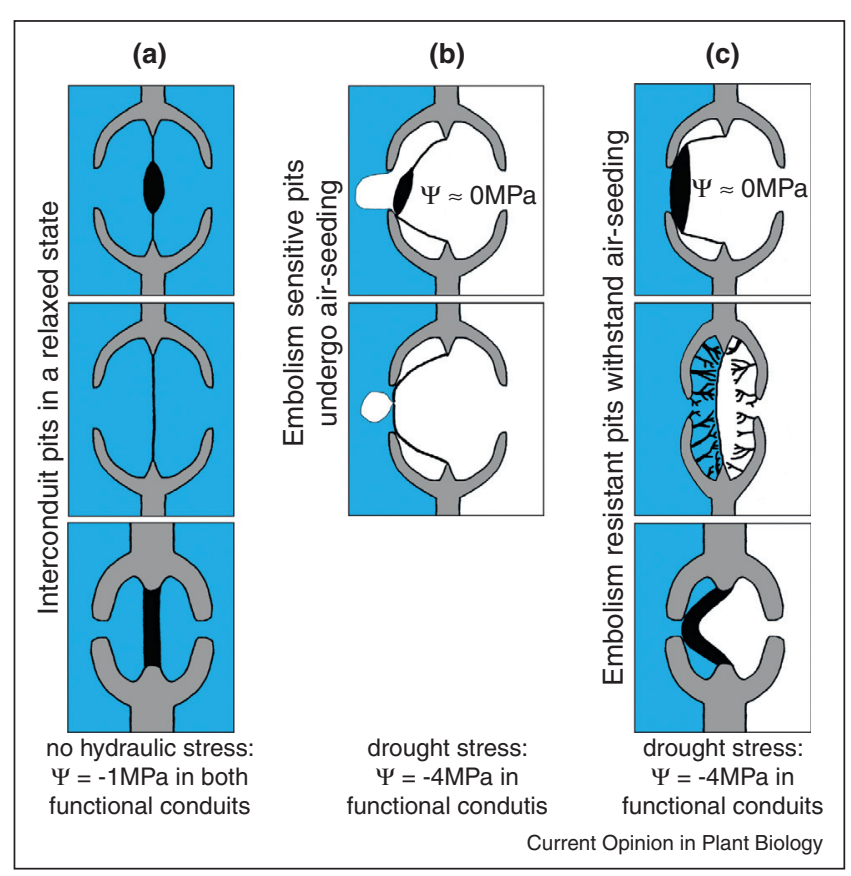

Fine-scale interconduit pit adaptations regulating drought-induced embolism in gymnosperms and angiosperms. Interconduit pits showing torus-margo pit membranes in gymnosperms (top row) and homogeneous pit membranes in angiosperms (middle and bottom rows). (a) Pit membranes in a relaxed state between two functional conduits facing no hydraulic stress. (b) and (c) A prolonged period of drought increases the pressure difference between the water-filled and the embolized conduit, causing the porous pit membranes to deflect. At a critical pressure difference, the capillary seal can give way, allowing air-seeding among adjacent conduits that exacerbates the water flow towards the leaves. Column c illustrates adaptations in pit quality characters that can prevent air-seeding at the same pressure difference, in comparison to the embolism sensitive pits shown in column b, such as the increased size ratio of tori versus pit aperture diameters in gymnosperms (top), and the presence of highly developed vestures (middle) or thicker pit membranes with reduced pores in angiosperms (bottom).

free to expand to fill the conduit and produce an embolism as water is drained by the surrounding transpiration stream. The evidence for air-seeding is that negative embolism pressures are usually equal and opposite to the pressure required to inject air into the intact conduits [13].

Important sites for air-seeding are openings in the secondary walls of neighbouring conduits called interconduit pits (Figure 1 [12]). These pits function to restrict the spread of air throughout the conduit network in the event of conduit damage, but at the same time allow lateral water transport via pores in the pit membranes (PMs). Conduits become damaged and air-filled not only during the course of normal development in the case of ruptured protoxylem strands, but also from abscission, breakage, herbivory, or other damage, although it remains to be explored whether there are other causes for air-filled vessels. The nano-scale pores of the interconduit PMs are narrow enough to trap the meniscus against a substantial pressure difference between an embolized and a functional conduit, thus inhibiting air entry under normal conditions. But when the pressure difference becomes too large during drought, the capillary seal can give way, causing air-seeding through interconduit PMs (Figure 1b). In this way, embolism propagates from conduit to conduit. The amount of embolized cells can be measured in terms of loss of hydraulic conductivity at various negative pressures, resulting in so-called vulnerability curves (VCs, Figure 2). Since VCs measure embolism rates, and because not all cavitation events must necessarily lead to embolism formation, 'embolism resistance' is a more correct term for the commonly used 'cavitation resistance' in plant physiology.

\section{Frost-induced embolism}

Embolism formation can also develop due to freeze-thaw cycles, and mainly depends on the diameter of the conduits [14-15]. Air is insoluble in ice, forming gas bubbles in the conduits during freezing. On thawing, these bubbles may expand when the negative pressure allows countering the bubble-collapsing force of the surface tension (thaw-expansion hypothesis). Consequently, frost-induced embolism can be amplified by drought stress [16-17].

\section{Fine-scale interconduit pit adaptations regulate drought-induced embolism resistance \\ Mechanical behaviour of pit quality characters}

Ultrastructural modifications of interconduit pits are good predictors to explain embolism resistance via air-seeding [18-22]. Within angiosperms, the huge variation in PM thickness (70-1900 nm) and maximum PM porosity (10$225 \mathrm{~nm}$ ) show that species with thicker PMs have smaller PM pores and are better adapted to avoid air-seeding (Figure 1c bottom [19]). Thicker PMs are also presumed to be mechanically stronger, causing more resistance to stretching and preventing PM pores to become larger [18,24]. Likewise, narrower pit chambers [22,25] and vestured pits (Figure 1c middle [23]) prevent excessive PM deflection in some groups. The mechanical behaviour of pits and their PMs remains to be investigated thoroughly, and therefore also PM chemistry [26] needs special attention with reference to the pit type and developmental stage. Noncellulosic compounds, such as pectins and hemicelluloses, occur in gymnosperm PMs [27], but the chemical composition of angiosperm PMs seems to be more diverse [18,28-29]. According to recent studies, intervessel PMs contain little or no pectic homogalacturonans and rhamnogalacturonan-I [29-30], which raises serious doubts about the swelling/shrinking hypothesis of interconduit PMs related to the ionic effect [31-34]. 
Figure 2

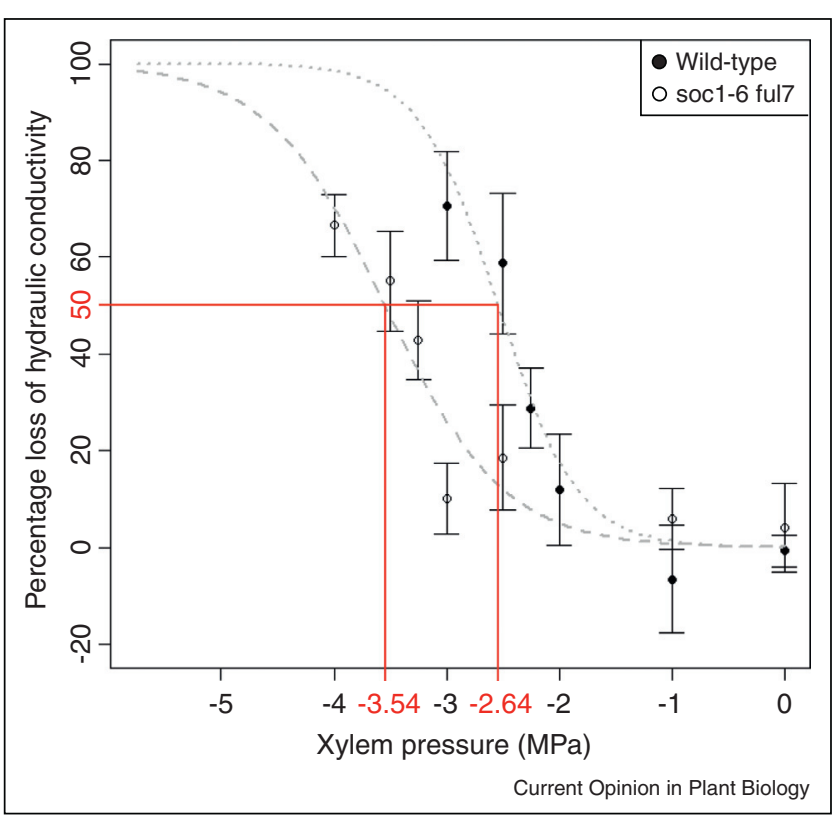

Xylem vulnerability to embolism in Arabidopsis thaliana wild-type (WT) and the woody soc1-6 ful7 mutant. Vulnerability curves of the WT (closed circles) and the mutant (open circles) show a significant difference (Student's $t$-test, $P<0.05$ ). The $\mathrm{P} 50$, or the pressure inducing $50 \%$ loss of hydraulic conductivity due to embolism formation, corresponds to $-3.54 \mathrm{MPa}$ in the woody mutant stems versus $-2.64 \mathrm{MPa}$ in the WT stems (red lines). Plants were grown under long days ( 16 hours light per day). Each data point represents the mean value from two to four plants and bars represent standard errors. Dotted grey lines are sigmoidal regressions.

Within conifers, embolism resistance of torus-margo pits in unicellular tracheids seems most closely correlated to the size ratio of torus versus pit aperture diameter [20$21,25]$. This suggests that the adhesion of the torus to the pit border is a major determinant of drought-induced embolism resistance (seal capillary-seeding, Figure 1c top [20]), although some conifer species show plasmodesmatal pores in their tori assuming air-seeding through these tori pores [35].

\section{Pit quantity characters}

The chance of initiating air-seeding through a single PM with large pores appears to be larger when more intervessel pits per vessel are present (rare pit hypothesis [36]). However, while the link between pit quantity per vessel and vulnerability to embolism is demonstrated in some angiosperm groups [37], it is lacking in others [22]. Opponents of the rare pit hypothesis use the quantity of intervessel pits per vessel to explain why long-vesseled species usually show vulnerable embolism rates [37-38]. The vulnerability of large vessels, however, is the subject of contradictory opinions. For instance, recent studies in grapevine based on a wide range of traditional and upto-date in vivo techniques suggest that the high embolism ratios in long-vesseled species may be a typical problem of the commonly used centrifuge technique [39-41], while others finding no long-vessel artefact [42].

\section{More evidence for the mechanical-functional trade-off in xylem \\ Wood density and thickness-to-span ratio}

Embolism resistant species are often characterized by a high wood density and a high thickness-to-span ratio of water conducting cells [43-45], and some studies have also highlighted increased fibre wall area, Modulus of Elasticity, and Modulus of Rupture as additional tradeoffs [44]. The mechanical reinforcement in droughtinduced embolism resistant wood is often explained by the stronger negative pressures in the conduits. Nevertheless, conduit implosion due to negative pressures has never been observed in wood. Alternatively, conduit wall reinforcement might prevent microfractures in walls [44] that in turn might trigger heterogeneous nucleation from air particles in walls or in intercellular spaces. But again, there is no experimental evidence for these microfractures, leaving the underlying mechanisms for the mechanical-functional trade-off in the xylem tissue unresolved.

\section{A new additional evolutionary hypothesis for secondary woodiness}

The existing mechanical-functional correlation in xylem can be translated into a novel hypothesis explaining why the habit shift from herbaceousness towards secondary woodiness (SW) occurs in some angiosperms. This habit shift was initially observed on islands by Charles Darwin and described as insular woodiness [46]. Today, several hypotheses are raised explaining why herbaceous lineages undergo massive convergent evolutionary shifts towards SW shrubs (summarized in [47]), but compelling evidence for this increased woodiness remains absent. Our Canary Island review shows that many of the SW species are native to the markedly dry coastal regions, suggesting for the first time a link between increased woodiness and embolism resistance [48 ${ }^{\bullet}$. However, we want to emphasize that many SW lineages also occur in very wet environments, suggesting the involvement of multiple environmental factors. For instance, lack of frost is an important criterion influencing the occurrence of SW [49].

Embolism measures in herbaceous species are scarce because of their fragile stems. Not surprisingly, the few herbaceous species studied do have rigid stems, such as

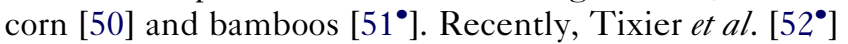
have managed to reconstruct VCs from the fragile herbaceous Arabidopsis thaliana stems. They demonstrate that short-day plants with slightly more wood development at the base of their stems are significantly more embolism resistant than long-day plants with less wood development, supporting the above-mentioned trade-off. We go one step further and compare the herbaceous wild-type 
with the shrubby $A$. thaliana mutant $\left[53,54^{\bullet}\right]$. The VCs of the woody mutant stems show significantly lower embolism rates than VCs of the herbaceous accession grown under the same growth conditions (Figure 2). This is the first experimental evidence supporting increased embolism resistance in SW shrubs compared to their herbaceous relatives.

\section{Different strategies in embolism resistance between angiosperms and gymnosperms High risk versus safety}

Angiosperms and gymnosperms have a strikingly different strategy to cope with drought-induced embolism resistance: the majority of angiosperms show a risky behaviour and operate close to their lethal hydraulic limit (i.e. pressure resulting in 70-80\% loss of conductivity), while most of the gymnosperms develop a much safer hydraulic margin that is further away from their lethal $50 \%$ boundary $\left[3,4,7^{\bullet \bullet}\right]$. The greater ability of angiosperms versus gymnosperms to repair stem embolisms may partly explain this different strategy $\left[55^{\circ}\right]$.

\section{Refilling embolized conduits}

Positive xylem pressures have been linked to vessel refilling in a variety of angiosperms, such as temperate woody trees [56], woody tropical plants [57], and many herbaceous species [ $\left.51^{\circ}\right]$. Refilling has also been reported under negative pressures, for instance in bay laurel [58] and rice [59], and requires pressures that need to rise close to atmospheric levels while the bulk xylem remains under negative pressure [60]. This seems contradictory, but what we do know is that sugars and ions from living xylem and phloem cells are involved [58,60-61]. This is demonstrated by amongst others girdling experiments $[38,58]$ and the observed transport of water and solutes between phloem and xylem [62].

\section{Conclusion and future prospectives}

Various structure-function relationships in the xylem are known to play a role in embolism resistance. Pit membrane thickness and porosity are crucial to prevent drought-induced embolism via air-seeding, and more insights into PM composition in different cell types in the xylem of angiosperms are urgently desired to understand the interaction between the dead conduits and the living cells. Emphasis is also placed on trade-offs between mechanical wood properties and embolism resistance, and is further supported by original embolism measures showing that stems of secondarily woody Arabidopsis mutants are more embolism resistant than the ones of the herbaceous wild-type.

The self-regulation of water flow (ionic effect) and refilling of embolized conduits suggest that water transport does not entirely rely on a passive cohesion-tension process, but also requires input from living cells. Future research should focus on these refilling mechanisms, and continue to elaborate on a broad-scale integrative approach linking xylem and phloem physiology with

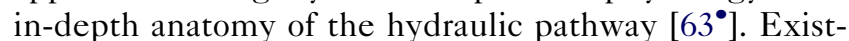
ing database projects, such as TRY [64] and the Xylem Functional Traits database $\left[7^{\bullet \bullet}\right]$, are the necessary first steps to accomplish this effort. Once we know the crucial features characterizing embolism formation and refilling in plants, we can find and manipulate the genes underlying these characters using woody model species [65] and apply it to tree forest species. A global analysis on the vulnerability of forests to drought shows that many trees operate with narrow hydraulic safety margins, inferring that embolism-related research will become increasingly important under the current Climate Change predictions $\left[7^{\circ \bullet}\right]$.

\section{Conflict of interests}

The authors declare that they have no competing interests.

\section{Acknowledgements}

This research was funded in part by the PitBulles project (ANR no 2012 Blan 171001 to HC and SH), and a NSF-IBN-0743148 project granted to JSS.

\section{References and recommended reading}

Papers of particular interest, published within the period of review, have been highlighted as:

- of special interest

$\bullet$ of outstanding interest

1. Dixon H, Joly J: On the ascent of sap. Ann Bot (Lond) 1894, 8:468-470.

2. Steudle E: The cohesion-tension mechanism and the acquisition of water by plant roots. Annu Rev Physiol Plant Mol Biol 2001, 52:847-875.

3. Brodribb TJ, Bowman D, Nichols S, Delzon S, Burlett R: Xylem function and growth rate interact to determine recovery rates after exposure to extreme water deficit. New Phytol 2010, 188:533-542.

4. Anderegg WRL, Berry JA, Smith DA, Sperry JS, Anderegg LDL, Field CB: The roles of hydraulic and carbon stress in a widespread climate-induced forest die-off. Proc Natl Acad Sci USA 2012, 109:233-237.

5. Brodribb TJ, Cochard $\mathrm{H}$ : Hydraulic failure defines the recovery and point of death in water-stressed conifers. Plant Physiol 2009, 149:575-584.

6. Kursar TA, Engelbrecht BMJ, Burke A, Tyree MT, El Omari B, Giraldo JP: Tolerance to low leaf water potential status of tropical tree seedlings is related to drought performance and distribution. Funct Ecol 2009, 23:93-102.

7. Choat B, Jansen S, Brodribb TJ, Cochard H, Delzon S, Bhaskar R,

- Bucci S, Feild TS, Gleason SM, Hacke U et al:: Global convergence in the vulnerability of forests to drought. Nature 2012, 491:752-756.

A global analysis on the vulnerability to drought in 266 forest species worldwide shows that most species operate with narrow hydraulic safety margins. These margins are largely independent from current mean annual precipitation.

8. Caupin F, Arvengas A, Davitt K, Azouzi MEM, Shmulovich KI, Ramboz C, Sessoms DA, Stroock AD: Exploring water and other liquids at negative pressure. J Phys Condens Matter 2012, 24:284110. 
9. Maherali H, Pockman WT, Jackson RB: Adaptive variation in the vulnerability of woody plants to xylem cavitation. Ecology 2004 85:2184-2199.

10. Willson CJ, Manos PS, Jackson RB: Hydraulic traits are influenced by phylogenetic history in the drought-resistant, invasive genus Juniperus (Cupressaceae). Am J Bot 2008, 95:299-314.

11. Cochard H: Cavitation in trees. C R Physique 2006, 7:1018-1026.

12. Zimmermann MH: Xylem Structure and the Ascent of Sap. Springer; 1983.

13. Cochard $\mathrm{H}$, Cruiziat $\mathrm{P}$, Tyree MT: Use of positive pressures to establish vulnerability curves: further support for the airseeding hypothesis and implications for pressure-volume analysis. Plant Physiol 1992, 100:205-209.

14. Davis SD, Sperry JS, Hacke UG: The relationship between xylem conduit diameter and cavitation caused by freezing. Am J Bot 1999, 86:1367-1372.

15. Pittermann J, Sperry JS: Tracheid diameter is the key trait determining the extent of freezing-induced embolism in conifers. Tree Physiol 2003, 23:907-914.

16. Pittermann J, Sperry JS.: Analysis of freeze-thaw embolism in conifers. The interaction between cavitation pressure and tracheid size. Plant Physiol 2006, 140:374-382.

17. Mayr S, Sperry JS.: Freeze-thaw induced embolism in Pinus contorta: centrifuge experiments validate the 'thawexpansion hypothesis' but conflict with ultrasonic emission data. New Phytol 2010, 185:1016-1024.

18. Choat $B$, Cobb A, Jansen S: Structure and function of bordered pits: new discoveries and impacts on whole plant hydraulic function. New Phytol 2008, 177:608-626.

19. Jansen $S$, Choat $B$, Pletsers $A$ : Morphological variation of intervessel pit membranes and implications to xylem function in angiosperms. Am J Bot 2009, 96:409-419.

20. Delzon S, Douthe C, Sala A, Cochard H: Mechanism of waterstress-induced cavitation in conifers: bordered pit structure and function support the hypothesis of seal-capillary seeding Plant Cell Environ 2010, 33:2101-2111.

21. Pittermann J, Choat B, Jansen S, Stuart SA, Lynn L, Dawson T: The relationships between xylem safety and hydraulic efficiency in the Cupressaceae: the evolution of pit membrane form and function. Plant Physiol 2010, 153:1919-1931.

22. Lens F, Sperry JS, Christman MA, Choat B, Rabaey D, Jansen S: Testing hypotheses that link wood anatomy to cavitation resistance and hydraulic conductivity in the genus Acer. New Phytol 2011, 190:709-723.

23. Choat B, Jansen S, Zwieniecki MA, Smets E, Holbrook NM: Changes in pit membrane porosity due to deflection and stretching: the role of vestured pits. J Exp Bot 2004, 55:15691575 .

24. Sperry JS, Hacke U: Analysis of circular bordered pit function. I. Angiosperm vessels with homogeneous pit membranes. Am Bot 2004, 91:369-385.

25. Hacke UG, Jansen S: Embolism resistance of three boreal conifer species varies with pit structure. New Phytol 2009, 182:675-686.

26. Herbette $\mathrm{S}$, Cochard $\mathrm{H}$ : Calcium is a major determinant of xylem vulnerability to cavitation. Plant Physiol 2010, 153:1932-1939.

27. Bauch J, Liese W, Scholz F: Über die Entwicklung und stoffliche Zusammensetzung der Hoptüpfelmembranen von Längstracheiden in Coniferen. Holzforschung 1968, 22:144-153.

28. Gortan E, Nardini A, Salleo S, Jansen S: Pit membrane chemistry influences the magnitude of ion-mediated enhancement of xylem hydraulic conductivity in four Lauraceae. Tree Physiol 2011, 31:48-58.

29. Plavcová L, Hacke UG: Heterogenous distribution of pectin epitopes and calcium in different pit types of four angiosperm species. New Phytol 2011, 192:885-897.
30. Plavcová L, Hacke UG, Sperry JS: Linking irradiance-induced changes in pit membrane ultrastructure with xylem vulnerability to cavitation. Plant Cell Environ 2011, 34:501-513.

31. Zwieniecki MA, Melcher PJ, Holbrook NM: Hydrogel control of xylem hydraulic resistance in plants. Science 2001, 291: 1059-1062.

32. van leperen W: lon-mediated changes of xylem hydraulic resistance in planta: fact or fiction? Trends Plant Sci 2007, 12:137-142.

33. Jansen S, Gortan E, Lens F, Lo Gullo MA, Trifilò P, Scholz A, Salleo $S$, Stein A, Nardini A: Do quantitative vessel and pit characters account for ion-mediated changes in the hydraulic conductance of xylem across angiosperms? New Phytol 2011, 189:218-228.

34. Nardini A, Salleo S, Jansen S: More than just a vulnerable pipeline: xylem physiology in the light of ion-mediated regulation of plant water transport. J Exp Bot 2011, 62 : 4701-4718.

35. Jansen S, Lamy J-B, Burlett R, Cochard H, Gasson P, Delzon S: Plasmodesmatal pores in the torus of bordered pit membranes affect cavitation resistance of conifer xylem. Plant Cell Environ 2012, 35:1109-1120.

36. Christman MA, Sperry JS, Adler FR: Testing the 'rare pit' hypothesis for xylem cavitation resistance in three species of Acer. New Phytol 2009, 182:664-674.

37. Hacke U, Sperry JS, Wheeler JK, Castro L: Scaling of angiosperm xylem structure with safety and efficiency. Tree Physiol 2006, 26:689-701.

38. Christman MA, Sperry JS, Smith DD: Rare pits, large vessels and extreme vulnerability to cavitation in a ring-porous tree species. New Phytol 2012, 193:713-720.

39. Choat B, Drayton WM, Brodersen C, Matthews MA, Shackel KA, Wada $\mathrm{H}$, McElrone AJ: Measurement of vulnerability to water stress-induced cavitation in grapevine: a comparison of four techniques applied to a long-vesseled species. Plant Cell Environ 2010, 33:1502-1512.

40. Brodersen CR, McElrone AJ, Choat B, Matthews MA, Shackel KA: The dynamics of embolism repair in xylem: in vivo visualizations using high-resolution computed tomography. Plant Physiol 2010, 154:1088-1095.

41. McElrone AJ, Brodersen CR, Alsina MM, Drayton WM, Matthews MA, Shackel KA, Wada H, Zufferey V, Choat B: Centrifuge techniques consistently overestimates vulnerability to water stress-induced cavitation in grapevines as confirmed with high-resolution computed tomography. New Phytol 2012, 196:661-665.

42. Jacobsen AL, Pratt RB: No evidence for an open vessel effect in centrifuge-based vulnerability curves of a long-vesseled liana (Vitis vinifera). New Phytol 2012, 194:982-990.

43. Hacke UG, Sperry JS, Pockman WT, Davis SD, McCulloh KA: Trends in wood density and structure are linked to prevention of xylem implosion by negative pressure. Oecologia 2001, 126:457-461.

44. Jacobsen AL, Ewers FW, Pratt RB, Paddock WAlll, Davis SD: Do xylem fibers affect vessel cavitation resistance? Plant Physiol 2005, 139:546-556.

45. Chave J, Comes D, Jansen S, Lewis SL, Swenson NG, Zanne AE: Towards a worldwide wood economics spectrum. Ecol Lett 2009, 12:351-366.

46. Darwin C: On the Origin of Species by Means of Natural Selection. John Murray; 1859.

47. Whittaker RJ, Fernández-Palacios LM: Island Biogeography. edn 2. Oxford University Press; 2010.

48. Lens F, Davin N, Smets E, Del Arco M: Insular woodiness on the

- Canary Islands: remarkable cases of parallel evolution. Int $J$ Plant Sci, in press

This is the first comprehensive review dealing with the origin of woodiness of a particular region using data from wood anatomy and molecular phylogenetic studies. In total, 220 native insular woody species from 
15 families are found on the Canary Islands, of which most of them grow in the dry coastal regions.

49. Carlquist S: Island Biology. Columbia University Press; 1974.

50. Li Y, Sperry JS, Shao M: Hydraulic conductance and vulnerability to cavitation in corn (Zea mays L.) hybrids of differing drought resistance. Environ Exp Bot 2009, 66:341-346.

51. Cao K-F, Yang S-J, Zhang Y-J, Brodribb TJ: The maximum

- height of grasses is determined by roots. Ecol Lett 2012, 15:666-672.

The maximum heights of bamboo culms are closely predicted by the maximum measured root pressure overnight. The authors also demonstrate that water transport in these species is dependent on root pressure to repair hydraulic dysfunction.

52. Tixier A, Cochard H, Badel E, Dusotoit-Coucaud A, Jansen S, - Herbette S: Arabidopsis thaliana as a model species for xylem hydraulics: does size matter? J Exp Bot, submitted for publication

This paper provides for the first time VCs of the herbaceous mode Arabidopsis thaliana, showing that short-day plants producing more wood cells at the base of the stem are more embolism resistant than the long-day plants. This supports the view that Arabidopsis can be used as a new model for xylem hydraulics.

53. Melzer S, Lens F, Gennen J, Vanneste S, Rhode A, Beeckman T: Flowering-time genes modulate meristem determinacy and growth form in Arabidopsis. Nat Gen 2008, 40:1489-1492.

54. Lens F, Smets E, Melzer S: Stem anatomy supports Arabidopsis

- thaliana as a model for insular woodiness. New Phytol 2012, 193:12-17.

Wood anatomy of the double mutant of Arabidopsis agrees with other woody Brassicaceae that develop into shrubs in their natural environment. This offers new opportunities to use this woody phenotype as a new model to investigate the molecular pathway leading to wood formation.

55. Johnson DM, McCulloh KA, Woodruff DR, Meinzer FC: Hydraulic - $\quad$ safety margins an embolism reversal in stems and leaves: why are conifers and angiosperms so different? Plant Sci 2012, 195:48-53.

Conifer stems have greater hydraulic safety margins than those of angiosperms. On the other hand, leaves and roots of conifers embolize and refill more frequently than those of angiosperms, which could be related to low stomatal sensitivity and/or a lesser ability of conifers to repair stem embolisms.
56. Ewers FW, Améglio T, Cochard H, Beaujard F, Martignac M, Vandame $M$, Bodet $C$, Cruiziat $P$ : Seasonal variation in xylem pressure of walnut trees: root and stem pressures. Tree Physiol 2001, 21:1123-1132.

57. Fisher J, Angeles G, Ewers FW, López-Portillo J: Survey of root pressure in tropical vines and woody species. Int J Plant Sci 1997, 158:44-50.

58. Salleo S, LoGullo MA, Trifilo P, Nardini A: New evidence for a role of vessel-associated cells and phloem in the rapid xylem refilling of cavitated stems of Laurus nobilis L.. Plant Cell Environ 2004, 27:1065-1076.

59. Stiller V, Sperry JS, Lafitte R: Embolized conduits of rice (Oryza sativa, Poaceae) refill despite negative xylem pressure. $A m \mathrm{~J}$ Bot 2005, 92:1970-1974.

60. Zwieniecki MA, Holbrook NM.: Confronting Maxwell's demon: biophysics of xylem embolism repair. Trends Plant Sci 2009, 14:530-534.

61. Nardini A, Lo Gullo MA, Salleo S: Refilling embolized xylem conduits: is it a matter of phloem unloading? Plant Sci 2011, 180:604-611.

62. Metzner R, Thorpe MR, Breuer U, Blümler P, Schurr U, Schneider HU, Schroedr WH: Contrasting dynamics of water and mineral nutrients in stems shown by stable isotope tracers and cryo-SIMS. Plant Cell Environ 2010, 33: 1393-1407.

63. Carlquist S: How wood evolves: a new synthesis. Botany 2012 , 90:901-940.

This review presents a total evidence approach providing an up-to-date summary about the evolution of wood anatomical features embedded in an eco-physiological context.

64. Kattge J, Díaz S, Lavorel S, Prentice IC, Leadley P, Bönisch G, Garnier E, Westoby M, Reich PB, Wright IJ et al.: TRY - a global database of plant traits. Global Change Biol 2011, 17: 2905-2935.

65. Secchi F, Gilbert ME, Zwienicki MA: Transcriptome response to embolism formation in stems of Populus trichocarpa provides insights into signaling and the biology of refilling. Plant Physiol 2011, 157:1419-1429. 